independent assessments of the accident's aftermath and probable implications, at a time when they were sorely needed.

In recent years, however, UNSCEAR has seemed less useful. The cold war has ended, and above-ground nuclear testing is considered so gauche that even North Korea is unwilling to do it. The committee's weighty reports are no longer the first port of call for scientists studying the health effects of radiation, who prefer the convenience of online searches of the open literature. Even within UNSCEAR's small secretariat, some people wondered whether the committee had run its course.

And then, in 2011, came the meltdowns at the Fukushima Daiichi nuclear plant in Japan. Three reactors released radioactive contaminants into the environment and forced the evacuation of thousands of people. Phones at UNSCEAR started to ring again.

Asked to investigate, the committee brought together dozens of scientists from universities and government agencies around the world to review the available data. They are now mid-way through their work, and much remains to be done, but already the value of the exercise, and of the organization behind it, is becoming clear.

In the days after the Fukushima accident, Japanese citizens were bombarded with radiation readings. The numbers were delivered in obscure units with little or no context, along with limp reassurances from government authorities. The data were inconsistent, and frequently wrong. Those early readings have been followed by government surveys, academic assessments and independent models of varying quality and message. The cacophony has fed mistrust and fear among local residents and the wider public.

UNSCEAR, however, is carefully reviewing the shaky readings taken during the early days of the accident to establish which of them are useful. It is integrating data from a wide range of sources to see what information has been collected and how it has been calibrated. And it is building its own models to reconstruct exactly what was emitted by the reactors and when. The aim is to come up with a coherent picture of the accident by the end of next year. Much remains to be done, but

this week UNSCEAR's working committee on Fukushima has been able to provide a comprehensive - and seemingly reassuring — view of radiation exposure among workers at the plant. That, combined with the available data on public exposure, indicates to many experts that the health effects from the accident will be minimal (see page 423 ).

Although some of the committee's scientists believe that its work will provide a measure of reassurance to the people of Japan, that is by no

"UNSCEAR will provide a strong, scientifically sound account of the Fukushima accident." means certain. Many of UNSCEAR's members come from regulatory bodies in their home nations - what critics of the nuclear industry view as the establishment. As such, they may struggle to convince outsiders that they act in good faith. One way to build support and bridges with potential critics might be to take more seriously the data collected by independent groups such as concerned citizens and international nongovernmental organizations in the immediate aftermath of the disaster. The committee is already considering this, and it should proceed.

There will remain limits to the comfort that science can provide. Cancer is a disease of statistics: some workers will get ill and some will blame it on the dose they received. Indeed, one has already died of leukaemia that is, as far as anyone can tell, unrelated to the accident.

Nevertheless, UNSCEAR has been reborn. The committee is no longer a clearing house - it is a filter. Its work in the coming months and years will provide a strong, scientifically sound account of the Fukushima accident. It will bring consistency to the numbers and mould a single narrative from the disparate data sets. Not everyone will agree with the committee's conclusions, but they will provide a definitive point of reference for discussion and evaluation.

Accidents such as that at Fukushima are thankfully rare, and within a few years UNSCEAR may fade back into obscurity. It can be allowed to slumber, but it must not be forgotten. In the modern information age, its purpose is clearer than ever before.

\section{A whale of a story}

\section{A previously unknown sensory organ provides a lesson in coordination.}

“T To produce a mighty book, you must choose a mighty theme. No great and enduring volume can ever be written on the flea, though many there be that have tried it." Herman Melville, the author of Moby Dick and of that quote, certainly knew a mighty theme when he saw one. His masterpiece is as much a study on the behaviours of the sperm whales that Melville saw while serving on a whaling ship as it is an exploration of the motives and characters of the men who pursue them.

Sperm whales (Physeter catodon) have teeth, as Melville and his fictional Captain Ahab knew all too well. So how they catch and eat their prey, although a mighty theme, is not much of a story. More interesting, and much more mysterious, is how rorqual whales - those toothless giants of the oceans - manage to synchronize the multiple complex processes that they use to survive on little more than krill and small fish.

These creatures, which include the fin (Balaenoptera physalus), humpback (Megaptera novaeangliae) and blue whale (Balaenoptera musculus), have long puzzled biologists. How can they survive and sustain their huge bodies on such a meagre diet? How can they get enough food? The answer involves one of the greatest feats in the animal kingdom.

Rorqual whales capture much of their food by an extraordinary procedure known as lunge feeding. When a rorqual comes across a dense patch of prey, it accelerates through the water and open its mouth. As it does so, its mouth fills with water, suspended within which are the tiny animals that the whale wants. The amount of water that flows into the whale can more than double the creature's weight, and to accommodate it, blubbery pleats under the lower jaw expand, just as an accordion grows as it fills with air. The once sleek and streamlined whale now has the shape of a bloated tadpole. And it has a lot of water in its mouth.

To squeeze the water out again, the whale closes its jaws and pushes the water out through plates of keratin filters, which trap the food. In this way, rorqual whales can gulp and graze for hours, repeatedly slowing down then lunging through the water.

It is a unique process, and one that requires some special equipment. The shape of a rorqual's head is more reptilian than mammalian, with a giant skull and mandibles that are held together by unique jaw joints made from dense elastic matrices of fibre and cartilage and infused with oil. This system lets the whale open its jaws to nearly a right angle - ideal for gulping water. There is more: the lower mandible has a flexible joint at its centre, which allows the two sides to rotate. And the whale can turn its tongue inside out, pulling it backwards to create even more space for the water. As it does so, its open mouth experiences massive drag, which the creature mitigates by contracting its throat to force some of the water back out.

But how on Earth does a rorqual manage to coordinate this activity? On page 498, Nicholas Pyenson of the Smithsonian Institution in Washington DC and his colleagues describe a sensory organ that they discovered in the jaws of several species that might offer an answer. The organ, they say, seems to be involved in several lunge-feeding pro-
DNATURE.COM To comment online, click on Editorials at: go.nature.com/xhunqu cesses, including the opening of the jaws and the expansion of the throat. And that means that it may have helped to drive the evolution of the huge bodies of rorqual whales - their great and enduring volumes, as Melville might have put it. 